\title{
PROGRAMA DE PROTEÇÃO E FACILITAÇÃO À CONVIVÊNCIA HARMÔNICA: UMA NOVA EXPERIÊNCIA NO CONTEXTO DO ENSINO JURÍDICO
}

\author{
PROTECTION AND FACILITATION PROGRAM TO THE HARMONIC \\ ASSOCIATION: A NEW EXPERIENCE IN THE CONTEXT OF LEGAL \\ EDUCATION
}

\author{
Giselle Picorelli Yacoub Marques ${ }^{1}$ \\ Delton Ricardo Soares Meirelles ${ }^{2}$ \\ Esther Benayon Yagodnik ${ }^{3}$
}

\begin{abstract}
RESUMO: No processo de transformação que a sociedade contemporânea vem experimentando (HABERMAS), surge a necessidade de se repensar a adequação do ensino jurídico das faculdades de Direito ao modelo assistencialista tradicional de acesso à justiça que, atualmente, se limita ao incentivo de práticas litigiosas. Para tanto, na esteira da redemocratização da justiça (BOAVENTURA DE SOUZA SANTOS), o presente estudo busca demonstrar como o discurso de Habermas auxilia a implantação de formas alternativas de resolução de conflitos no âmbito do Núcleo de Prática Jurídica da Universidade Federal Fluminense, por meio de ações de extensão acadêmica. O Programa de Proteção e Facilitação da Convivência Harmônica, sendo ação de extensão inovadora neste sentido, alcança, através da identificação do conflito real pelo diálogo entre os agentes sociais envolvidos no conflito, e, tomando por base o agir comunicativo (HABERMAS), um viés emancipatório, para além da simples "compensação" do dano causado, atingindo também a efetividade do acesso à justiça e aos direitos. Incentiva-se a prática centrada no empenho e comprometimento dos participantes na elaboração e observância das normas por eles mesmos criadas, possibilitando um consenso pautado na ética, dignidade e retomada da responsabilidade, permitindo a desconstrução dos conflitos e reconstrução das relações.
\end{abstract}

Palavras-chave: Acesso à Justiça. CAJUFF. Ensino jurídico. Formas alternativas de resolução de conflitos. Programa de Proteção e Facilitação da Convivência Harmônica.

\footnotetext{
${ }^{1}$ Doutoranda e Mestre pelo Programa de Pós-Graduação em Sociologia e Direito PPGSD/UFF. Pesquisadora do LAFEP/UFF. Professora auxiliar do departamento de Direito Privado da Universidade Federal Fluminense. E-mail: gisellepicorelli@hotmail.com

${ }^{2}$ Coordenador de graduação e professor adjunto do Departamento de Direito Processual da Universidade Federal Fluminense (SPP/UFF) e do corpo permanente do Programa de PósGraduação em Sociologia e Direito (PPGSD/UFF). Coordenador do Laboratório Fluminense de Estudos Processuais (LAFEP/UFF). Doutor em Direito (UERJ). E-mail: deltonmeirelles@ig.com.br

${ }^{3}$ Mestranda pelo Programa de Pós-Graduação em Sociologia e Direito - PPGSD/UFF. Pesquisadora do LAFEP/UFF. Professora auxiliar do Centro de Assistência Judiciária da Universidade Federal Fluminense. Coordenadora da ação de extensão Programa de Proteção e Facilitação da Convivência Harmônica, em desenvolvimento na Universidade Federal Fluminense - UFF. E-mail: estherbenayon@gmail.com
}

REVISTA DO DIREITO UNISC, SANTA CRUZ DO SUL № $40 \mid$ p. 164 - 183|AGO - OUT 2013 
ABSTRACT: In the process of transformation that contemporary society is experiencing (Habermas), there is a need to rethink the adequacy of legal education from law schools to traditional welfare model of access to justice, which currently is limited to encouraging practices litigatio. Therefore, in the wake of the democratization of justice (BOAVENTURA DE SOUZA SANTOS), this study seeks to show how the discourse of Habermas assists the deployment of alternative forms of conflict resolution within the Center for Legal Practice, Fluminense Federal University, through actions of academic extension. The Protection and Facilitation Program to the Harmonic Association is being innovative extension action in this direction, reaches through the identification of the actual conflict through dialogue among the social agents involved in the conflict, and, based on communicative action (Habermas), a bias emancipatory, beyond simply "offset" the damage, affecting the effectiveness of access to justice and rights. Encourages the practice centered on dedication and commitment of the participants in the formulation and observance of rules created by them, enabling a consensus guided by ethics, dignity and resumption of responsibility, allowing the deconstruction and reconstruction of conflict relations.

Keywords: Access to Justice. CAJUFF. Legal education. Alternative forms of conflict resolution. Protection and Facilitation Program to the Harmonic Association.

\section{CONSIDERAÇÕES INICIAS}

A partir do presente estudo, que envolve uma perspectiva interdisciplinar e busca aproximar áreas de conhecimento das ciências sociais aplicadas e das ciências humanas, surge a necessidade de se repensar a adequação do ensino jurídico das faculdades de Direito ao modelo assistencialista tradicional de acesso à justiça que, atualmente, se limita ao incentivo de práticas litigiosas, confeccionado na esteira da Constituição da República Federativa do Brasil de 1988.

A atual proposta de ensino jurídico, em especial no aprimoramento da prática, tem seu foco direcionado para a solução do litígio, baseado na disputa adversarial, levando a busca por um "vencedor". Contudo, diante do constante processo de transformação que a sociedade contemporânea vem experimentando e a demanda por práticas mais adequadas às necessidades $\mathrm{e}$ peculiaridades dos conflitos sociais, se torna necessário buscar outros modelos de abordagem dos litígios, visando à efetividade dos direitos. 
Para tanto, encontra-se em desenvolvimento ações de extensão, no âmbito do núcleo de prática jurídica da Universidade Federal Fluminense, mormente a ação intitulada Programa de Proteção e Facilitação da Convivência Harmônica, que permite introduzir a teoria do agir comunicativo (HABERMAS) à categoria do direito moderno e da resolução adequada de conflitos.

A ação de extensão, que tem como público alvo o institucional (estudantes, professores, servidores e funcionários técnico-administrativos) e social (cidadãos), residentes na municipalidade de Niterói, no Rio de Janeiro, convida, mediante veiculação nas principais mídias, aqueles que possuam conflitos de vizinhança ou de natureza familiar e que estejam dispostos a participar do projeto.

A proposta principal é contribuir com a facilitação da convivência harmônica, consolidando experiências de autocomposição de conflitos através do diálogo das partes, a partir de uma articulação entre alunos, professores e grupos sociais na perspectiva dos direitos humanos e da reconstrução da cidadania, permitindo, nesse sentido, uma resolução mais permanente e flexível ao conflito. Assim, objetiva-se a ampliação dessa cultura não litigiosa na busca pela solução pacífica do conflito pelas próprias partes envolvidas, através de comunicação ética, qualificando, desta forma, sua participação na sociedade e ampliando os espaços de cidadania.

\section{CRISE DO ENSINO JURÍDICO NO BRASIL E A PREMENTE NECESSIDADE DE TRANSFORMAÇÃO}

Uma breve análise da trajetória do ensino jurídico no Brasil permite concluir que o modelo de formação dos bacharéis, futuros profissionais e operadores do Direito, ainda é tradicionalista, calcado nas técnicas e nas práticas adversariais e litigiosas de resolução de conflitos. Em decorrência, podemos compreender o desconhecimento ou conhecimento carente por parte dos bacharéis, discentes e operadores de práticas alternativas de resolução de controvérsias, como a mediação, por exemplo, além de outras formas de facilitação do direito fundamental de acesso à justiça.

Fazendo uma retrospectiva histórica sintética, criados em 1827 no Brasil, os cursos de Direito eram sediados em dois conventos: o de São Francisco 
(São Paulo) e o de São Bento (Olinda). Os cursos foram criados apenas pela necessidade de se formar profissionais que atendessem às emergências do Estado Nacional da época, quais eram, a formação de advogados, julgadores e burocráticos das funções administrativas do Estado. Note-se, contudo a dissociação com questões sociais do contexto brasileiro da época.

Com a República, o ensino jurídico sofreu modificações, principalmente em razão da filosofia positivista, mas que não conseguiram repercussões estruturais significantes.

Em 1931, a Reforma Francisco Campos trouxe a orientação pelo ensino jurídico profissionalizante, pautados no estudo do Direito Positivo.

Com mais de cem anos de criação, afirmou Santiago Dantas (apud RODRIGUES, 2005, p.27), que a crise do ensino jurídico ainda se mantinha viva. O ensino jurídico, burocratizado, descontextualizado da realidade social e descompromissado com a questão da justiça, advertiu Santiago Dantas, declinava na qualidade e acarretaria uma perda de credibilidade.

Ocorre que até a presente data encontramos o mesmo sistema de ensino jurídico, que denota séria e complexa crise estrutural. Sobre esta complexa crise, Horácio Wanderlei Rodrigues (2005, p.34) se posiciona:

No quadro social, político e econômico brasileiro, uma série de fenômenos vem contribuindo para a crise do ensino do Direito. (...) Modificaram-se as exigências com relação à prática profissional do jurista, mas o ensino do Direito não acompanhou essa evolução. Continua inerte, estacionado na era dogmática, não tendo, em muitas situações, superado o século XIX, ainda reproduzindo a ideia de que a simples positivação dos ideais do liberalismo é suficiente para gerar a democracia e que o positivismo é o modelo epistemológico adequado para a produção do conhecimento científico.

Assim, observa-se que o ensino jurídico no Brasil é tradicionalmente conservador, voltado às práticas litigiosas e adversárias, não se levando em consideração o contexto social, mas sim um dogmatismo normativista.

Traçado o panorama da crise, se faz necessária a quebra desses paradigmas para adequar o ensino jurídico para além do modelo tradicional, com ênfase no contexto social em que pertencemos, procurando inserir nos cursos, entre outras propostas, a prática dialógica da resolução não adversarial de conflitos, como por exemplo, a conciliação e mediação. A educação dos 
discentes a esta prática é fundamental até porque há uma tendência de desformalização de controvérsias, desjudicialização de conflitos e ampliação do modelo assistencialista tradicional de acesso à justiça.

Seria interessante, portanto, que a mudança de paradigmas se iniciasse pelos cursos de Direito, na formação de profissionais capacitados em administrar conflitos sem judicializá-los. Contudo, isso não será possível, por já existirem iniciativas institucionais (Tribunais de Justiça, Ministério Público, Defensorias) que já praticam a mediação como modo alternativo de resolução de controvérsias.

Pioneiro ou não, o importante é que o ensino jurídico se adeque a esse novo enfoque, sobretudo para possibilitar o caminho evolutivo e o acompanhamento da sociedade com as práticas coexistenciais de resolução de conflitos, evitando a falência de instituições e do próprio sistema do Direito.

E este é o objetivo deste estudo e principalmente do Programa de Proteção e Facilitação da Convivência Harmônica: permitir, no âmbito da extensão acadêmica, a partir de construções teóricas interdisciplinares, o contato real de discentes, docentes e sociedade civil a conflitos que possam atingir seu fim através da resolução alternativa, sem que seja necessário recorrer ao Poder Judiciário.

\section{A BUSCA DO ACESSO À JUSTIÇA NA CONTEMPORANEIDADE}

Diante das características próprias referentes a etapa atual da sociedade em que vivemos, e da busca pelo amplo acesso à justiça, por meio da efetividade dos direitos, a exigência por práticas adequadas e sensíveis para resolução dos conflitos é cada vez maior.

A questão do acesso à Justiça, no sentido de se garantir ao cidadão o ingresso aos Tribunais e a efetivação dos seus direitos, vem sendo desenvolvida no decorrer dos anos no meio jurídico, tendo como ponto de partida, em especial, a obra de Mauro Cappelletti e Bryant Garth - "Acesso à Justiça”, decorrente do Florence Project (1973 a 1979).

Assim, a despeito do conceito tradicional de acesso à justiça, aqui se propõe uma complementação, podendo ser compreendido como também acesso aos meios de resolução de conflitos. 
Importante destacar que o Brasil não fez parte das análises de Cappelletti e Garth, sendo necessário o seguinte paralelo: a busca pela expansão do welfare state e a efetivação de novos direitos na década de 1960 foram a mola propulsora do crescimento dos estudos referentes ao acesso à Justiça, em especial nos países europeus (CAPPELLETTI, 1994, p.80).

Imprescindível, contudo, contar com as preciosas análises que Eliane Junqueira faz do acesso à justiça em nosso país, considerando sobretudo a realidade vivenciada no continente latino americano.

De acordo com a autora, precisa-se ter em mente que vivemos em um país que passou por experiências ditatoriais relativamente recentes, onde os mecanismos democráticas encontravam-se suspensos, dificultando o acesso aos direitos mais fundamentais.

Assim, no Brasil, a situação se mostrava um tanto quanto mais crítica, a necessidade era

de se expandirem para o conjunto da população direitos básicos aos quais a maioria não tinha acesso tanto em função da tradição liberal-individualista do ordenamento jurídico brasileiro, como em razão da histórica marginalização sócio-econômica dos setores subalternizados e da exclusão político-jurídica provocada pelo regime pós-64. (JUNQUEIRA, 1996, p.01)

Apesar de o Princípio do acesso à Justiça tornar possível o ingresso formal do cidadão nas instâncias judiciais, não pode significar apenas recursos que viabilizem tal ingresso, uma visão meramente formal deste princípio esculpido no artigo 5ํ, XXXV da Constituição Federal de 1988. O alcance real do acesso à Justiça deve ir além, possibilitando ao jurisdicionado não somente o acesso aos Tribunais, mas também a efetivação prática do seu direito; a realização objetiva do bem da vida pleiteado em juízo, devendo ser a efetividade considerada como um direito fundamental inerente à tutela jurisdicional.

Luiz Wernneck Vianna (1999, passim) coloca que após as reformas constitucionais de 1988, a sociedade brasileira passou a experimentar o direito em todos os âmbitos da vida política e social, no fenômeno denominado "judicialização das relações jurídicas e sociais". 
Diante de tal fenômeno, a necessidade do sistema jurídico, em especial o processual, atender às tarefas sociais a ele destinadas é essencial. Afirma Geovany Cardoso Jeveaux (2011, p.6) que "essas tarefas sociais destinadas ao processo devem coincidir com os objetivos eleitos pela sociedade política, nisso consistindo o resultado jurídico-substancial que dele se espera. Entre os vários fins almejados está o principal: a justiça (...)"

Outrossim, essa necessidade de aperfeiçoamento do processo a fim de que possa garantir um efetivo meio de acesso à Justiça, caminha junto ao importante desenvolvimento da própria atuação do Judiciário como ator responsável pela tramitação processual, sendo de Boaventura de Sousa Santos (2008, p.167/168) a seguinte lição:

... a constatação de que a organização da justiça civil e, em particular, a tramitação processual não podiam ser reduzidas à sua dimensão técnica, socialmente neutra, como era comum serem concebidas pela teoria processualista, devendo investigar-se as funções sociais por elas desempenhadas e, em particular, o modo como as opções técnicas no seu seio veiculam opções a favor ou contra interesses sociais divergentes ou mesmo antagônicos.

Nessa perspectiva, estando o sistema jurídico inserido nas transformações da sociedade contemporânea, a busca por um sistema jurídico que proporcione o real acesso à Justiça tem sido frequente, em especial através das reformas legislativas.

Contudo, tais reformas legislativas não terão o sucesso e assentimento desejados se não forem precedidas (i) do conhecimento e reflexão sociológicos, (ii) do auto-entendimento dos atores sociais envolvidos e (iii) da participação ativa dos concernidos, permitindo desenvolver normativas legitimadas pela participação da sociedade e que atendam à demanda da massa social de forma substancial, e não apenas na forma quantitativa de normas.

Sobre este viés da tensão existente entre assentimento, aceitação, validez social e legitimidade das normas, bem afirma Habermas (1989, p.82/83)

Em regra geral, o assentimento motivado racionalmente associar-se-á a uma aceitação empírica, ou seja, produzida pelas armas ou por bens materiais, numa crença na legitimidade cujos componentes não são 
simples de se analisar. Esses amálgamas, porém, são interessantes na medida em que constituem em indício de que não basta a entrada em vigor positivista das normas para assegurar duradouramente sua validez social. A imposição duradoura de uma norma depende também da possibilidade de mobilizar, num dado contexto da tradição, razões que sejam suficientes pelo menos para fazer parecer legítima a pretensa de validez no círculo das pessoas a que se endereça. Aplicado às sociedades modernas, isso significa: sem legitimidade, não há lealdade das massas. (grifos no original)

Desta forma, o resultado declarado pela legislação deve conter elementos que promovam a confiança e neste sentido importante destacar algumas regras elencadas por Jürgen Habermas ao trabalhar com a temática da ética do Discurso, com base no catálogo de pressupostos argumentativos de Alexy, como gerador de expectativas e coerência discursiva.

Seguindo as regras tomadas como exemplos, no plano lógicosemântico, temos como a primeira delas (i) "A nenhum falante é lícito contradizer-se", não sendo "lícito aos falantes usar a mesma expressão em sentidos diferentes." Com esta regra pretende-se manter a clareza e honestidade do discurso. "Neste plano estão pressupostos pragmáticos de uma forma especial da interação, a saber, tudo o que é necessário para uma busca cooperativa da verdade." (HABERMAS, 1989, p.110)

Neste mesmo sentido, vale destacar a reflexão de Zygmunt Bauman (2001, p.28) sobre a necessidade das normas e da clareza destas para a vida da sociedade, sendo a confiança fator importante no equilíbrio social

A ausência, ou mera falta de clareza, das normas anomia - é o pior que pode acontecer às pessoas em sua luta para dar conta de seus afazeres da vida. As normas capacitam tanto quanto incapacitam; a anomia anuncia a pura e simples incapacitação.

Na sequência das regras da argumentação, (ii) "a todo falante só é lícito afirmar aquilo em que ele próprio acredita", buscando-se, neste ponto, a verdade e simetria do discurso. "Neste plano, fazem-se valer pressuposições que o Discurso comparte com o agir orientado para o entendimento mútuo em geral (...)".(HABERMAS, 1989, p.111) 
Num terceiro momento, (iii) a regra esta baseada na possibilidade da participação ativa do sujeito no discurso, sendo este um elemento essencial da confiança, por ser gerador de legitimidade das decisões. Assim, no entender de Habermas (1989, p.112):

(3.1) É lícito a todo sujeito capaz de falar e agir participar de Discursos.

(3.2) a. É lícito a qualquer um problematizar qualquer asserção. b. É lícito a qualquer um introduzir qualquer asserção no Discurso. c. É lícito a qualquer um manifestar suas atitudes, desejos e necessidades.

(3.3) Não é lícito impedir falante algum, por uma coerção exercida dentro ou fora do Discurso, de valer-se de seus direitos estabelecidos em (3.1) e (3.2).

Continuando, explica Habermas cada uma das regras propostas:
A regra (3.1) determina o círculo dos participantes potenciais no sentido de uma inclusão de todos os sujeitos, sem exceção, que disponham da capacidade de participar em argumentações. A regra (3.2) assegura a todos os participantes chances iguais de contribuir para a argumentação e fazer valer seus próprios argumentos. A regra (3.3) exige condições de comunicação que tornem possível o prevalecimento tanto do direito a um acesso universal ao Discurso, quanto do direito a chances iguais de participar dele, sem qualquer repressão, por sutil e dissimulada que seja (e, por isso, de maneira igualitária). (HABERMAS, 1989, p.112)

Assim, é possível afirmar que, na busca por aprimorar o enfoque do acesso à Justiça, as reformas processuais devem ser realizadas visando atender as expectativas de um jurisdicionado que espera manter a confiança no sistema de forma a efetivar seus direitos, dentro de um tempo e espaço determinados, utilizando dos instrumentos de justiça social, não apenas uma justiça burocratizada.

Nesse passo, diante do elevado grau de complexidade social encontrada na trajetória do sistema, e com isso as novas demandas decorrentes de tais transformações, necessária uma observação atenta do alcance das possibilidades do sistema jurídico. As alterações na estrutura da sociedade geram diferentes possibilidades de conflitos, exigindo do Direito respostas adequadas a estas novas realidades. Com isso, o sistema social afeta diretamente a trajetória progressiva do sistema jurídico, impelindo-o a № 40|p. 164 - 183|AGO - OUT 2013 
acompanhar a transformação da sociedade. A influência, e porque não dizer a pressão, exercida pela sociedade sobre o Direito tem a condição de transformar e extrair novas respostas para estas novas possibilidades resultantes deste movimento social.

Desta forma, o que se propõe aqui, é uma abordagem dos meios alternativos de resolução de conflitos, principalmente a mediação, como um viés do acesso à justiça e também como uma proposta de um espaço onde o protagonismo dos cidadãos ao administrarem seus conflitos possa ser devolvido, tomando por base a teoria do agir comunicativo.

\section{MEDIAÇÃO COMO MEIO DE EMANCIPAÇÃO SOCIAL}

Considerando a pluralidade das sociedades contemporâneas, o sistema jurídico estatal, por meio da atuação do Poder Judiciário, nem sempre é o caminho mais efetivo e adequado na gestão intermitente de certos conflitos que surgem com o quotidiano da convivência. Existe uma iminente tensão no Poder Judiciário no que concerne ao acesso à justiça. Ao mesmo tempo em que foi facilitado o acesso (entrada formal) ao Poder Judiciário ao cidadão comum (através da criação dos juizados especiais, por exemplo), de tantas demandas, o mesmo se encontra atualmente assoreado, surgindo a necessidade da busca por uma maneira de se efetivar e garantir a tutela dos direitos e o concreto acesso à justiça.

Contudo, não apenas este acesso formal deve ser objeto das transformações do sistema, a preocupação com a real fruição dos direitos levou à redefinição do direito do acesso à justiça, cujo conteúdo deve superar a mera possibilidade de estar em juízo, acrescentando-se outros importantes aspectos, orientados à garantia de uma resposta efetiva.

$\mathrm{Na}$ atualidade estamos diante do fenômeno chamado por Kazuo Watanabe (2007, p.07) de "cultura da sentença". Os juízes preferem proferir sentença ao invés de tentar conciliar as partes para a obtenção da solução amigável dos conflitos. Sentenciar, em muitos casos, é mais fácil e mais cômodo do que pacificar os litigantes e obter, por via de consequência, a solução dos conflitos".

Ademais, acompanhado desta cultura da sentença, o Judiciário vivencia aguda crise e apresenta contumaz ineficácia da tutela prestada. A mudança de 
mentalidade é premente, devendo-se buscar outros meios de abordagem dos conflitos, uma justiça substancial, por meio de soluções pacíficas gerais, podendo ser elas dentro (endoprocessual) ou fora (extraprocessual) do processo.

É nesse contexto específico que surge a necessidade de redemocratização e da busca de uma justiça cidadã, que propõe ser inserida através de institutos tais como a mediação, no complexo de reformas processuais contemporâneas. Contudo, a própria sociedade brasileira ainda está carente de uma cultura voltada para a emancipação do indivíduo, uma cultura que trabalha com um terceiro no conflito que atue de maneira apenas gerencial e não de forma decisionária. Ao revés, ainda impera uma cultura litigiosa, conflitual.

Neste passo, a mediação surge como um mecanismo de desconstrução de conflitos, possibilitando o diálogo e ampliação da compreensão das partes, transformando-se a situação adversarial em uma situação de cooperação, promovendo assim, o acesso à Justiça na sua forma mais eficaz, que é o gerenciamento e, possível, solução efetiva do conflito, resposta tão almejada pela sociedade e pelo próprio Direito.

Assim, a mediação constitui um mecanismo fundamental para a instauração de uma sociedade direcionada para a harmonia entre seus membros, podendo-se entendê-la como um instrumento de exercício da cidadania na medida em que significa uma experiência pedagógica de resolução de conflitos, contribuindo para a superação de diferenças e para decisões que expressem efetivamente os interesses das partes envolvidas.

O desfecho do conflito se dará por meio da cooperação entre as partes e não por meio de qualquer tipo de imposição. A mediação permite aos adversários desenvolverem nova relação, baseada no respeito recíproco, mantendo cada qual sua identidade própria, permitindo "o aperfeiçoamento das relações, a superação de conflitos e a garantia de continuidade da sociedade humana" (HANSEN, 2011, p.102).

Como já se pôde observar do tópico anterior, o Direito, isoladamente tratado, não traz mais respostas satisfatórias aos anseios sociais e à busca pela justiça e seu efetivo acesso. Para tanto, trazemos aqui para enriquecer nossa argumentação, a própria proposta de Habermas, na obra Direito e 
Democracia. Entre Facticidade e Validade, qual seja, introduzir a categoria do direito moderno na ótica da teoria do agir comunicativo.

É que, após a confecção da obra, nos parece que o conceito de direito para Habermas se fecha através da ligação entre a teoria da ação comunicativa e Direito e Democracia. O Direito vai encontrar sua legitimidade através de procedimentos que perpassam por uma justificação moral que por sua vez validam as normas (formas jurídicas).

Da razão comunicativa externam-se pretensões de validade da verdade subjetiva; ela não é informativa (não determina a realização de tarefas práticas).

Mas aqui vamos pensar a mediação, na esteira do caminho da modernidade, não só como uma possibilidade normativa, mas sim como uma possibilidade normativa justificada (ou seja, aceita legitimamente). Complementando, não trataremos aqui de meros meios alternativos de resolução de conflitos, mas de meios adequados de resolução de conflitos.

A complementação das expressões resulta da própria insuficiência do Direito, mas de sua interdisciplinaridade com os campos sociológicos, antropológicos e filosóficos. É que, a depender do comprometimento dos cidadãos com a prática de resolução adequada e alternada de conflitos, surgirá uma "norma jurídica" inter partes, que, muitas vezes, de jurídica nada possui, porém com senso extremo de justiça, e de observância obrigatória...

Melhor explicando, o projeto de pacificação formulado pelas próprias partes mediadas em determinado contexto alcança, além de grau satisfatório de efetividade, a recomposição real do conflito, consequência por vezes distante do provimento jurisdicional, ainda que não seja essa a intenção do julgador.

Vale ressaltar que o consenso só será possível quando os interesses reais, as motivações ocultas dos mediandos forem expostas com boa-fé e debatidas, sem nenhum tipo de imposição ou determinação, sendo a solução produto deste consenso após a reflexão e articulação do dissenso. ${ }^{4}$

\footnotetext{
${ }^{4}$ Fazendo um paralelo com os ensinamentos de Jürgen Habermas (2010, p.142) é possível entender como a mediação e seu processo se estruturam: as partes envolvidas são os autores do acordo, sendo este resultante de uma comunicação aberta, esclarecida e com o assentimento dos participantes, de forma racional e fundada na responsabilidade. Por tudo isso, se torna legítimo e conscientemente aceitável pelos interessados. Nas palavras de Habermas: "São válidas as normas de ação às quais todos os possíveis
} 
Neste mesmo eixo de compreensão, temos que

examinada sob a ótica da teoria da comunicação, a mediação é um método que tem como fundamento teórico e técnico uma lógica própria. Consiste em um processo que transcende o simples conteúdo do conflito em questão: tem como objetivo a resolução da controvérsia associada a uma transformação positiva dos relacionamentos envolvidos. ${ }^{5}$

Assim, um consenso, fruto da composição amigável, tem mais chance de ser cumprido pelas partes do que uma decisão judicial imposta, ou seja, adquire maior legitimidade. Isto porque no acordo construído pelas partes, cada um tem consciência e aceita sua parcela de responsabilidade legitimamente. Não há perdedor e vencedor, a litigiosidade foi desfeita através do diálogo e cooperação, da ação comunicativa - restaurada pela mediação.

Pari passu, afirma Habermas (1989, p.86/92) que

De acordo com a ética do Discurso, uma norma só deve pretender validez quando todos os que possam ser concernidos por ela cheguem (ou possam chegar), enquanto participantes de um Discurso prático, a um acordo quanto à validez dessa norma.

(...)

... só quando a decisão resulta de argumentações, isto é, se ela se forma segundo as regras pragmáticas de um Discurso, que a norma decidida pode valer como justificada. Pois é preciso garantir que toda pessoa concernida tenha a chance de dar espontaneamente seu assentimento. A forma da argumentação deve evitar que alguns simplesmente sugiram ou mesmo prescrevam aos outros o que é bom para eles. Ela deve possibilitar, não a imparcialidade do juízo, mas a ininfluenciabilidade ou a autonomia da formação da vontade. Nesta medida, as regras do Discurso têm elas próprias um conteúdo normativo; elas neutralizam o desequilíbrio de poder e cuidam da igualdade de chances de impor os interesses próprios de cada um.

atingidos poderiam dar o seu assentimento, na qualidade de participantes de discursos racionais. (...) Eu entendo por 'normas de ação' expectativas de comportamento generalizadas temporal, social $e$ objetivamente. Para mim, 'atingido' é todo aquele cujos interesses serão afetados pelas prováveis conseqüencias provocadas pela regulamentação de uma prática geral através das normas. E 'discurso racional' é toda a tentativa de entendimento sobre pretensões de validade problemáticas, na medida em que ele se realiza sob condições da comunicação que permitem o movimento livre de temas $e$ contribuições, informações e argumentos no interior de um espaço público constituído através de obrigações ilocucionárias. Indiretamente a expressão refere-se também a negociações, na medida em que estas são reguladas através de procedimentos fundamentados discursivamente." (grifos do autor)

5 SARMENTO, Roselaine dos Santos. Mediação Familiar: um meio altamente eficaz de acesso à justiça, p.294. 
A forma da argumentação resulta assim da necessidade da participação e do equilíbrio de poder (...).

Assim, um acordo decorrente de um procedimento de mediação, com a utilização das técnicas adequadas a cada caso, poderá valer entre as partes concernidas com maior força e de mais efetividade que uma sentença judicial, pois o acordo foi resultado de um discurso baseado em uma argumentação participativa e no equilíbrio de poder dos envolvidos.

Ressalta-se que, em nosso entender, a mediação possui um viés integrador de um projeto civilizatório, eis que qualifica a cidadania e a participação efetiva social, sob o viés emancipatório.

No nosso ponto de vista, a mediação deveria ser um procedimento extrajudicial e também pré-processual, promovido antes da efetiva judicialização do conflito e da existência de um processo judicial para que alcance com propriedade suas características e objetivos : um instrumento de cidadania e Justiça social, como superação do conflito antes mesmo da busca pela institucionalização do litígio, seguindo parâmetros legais e socialmente aceitos pela coletividade.

Na mediação extrajudicial, é possível identificar a verdadeira matriz da mediação: a autonomia das partes. Dentro de um procedimento em que se busca a responsabilidade e liberdade das partes e, em decorrência, disto, a efetivação da democracia fora de um núcleo de poder institucionalizador, a mediação extrajudicial atinge sua finalidade sem estar maculada por possíveis vetores de poder.

Nesse contexto, a mediação é alternativa de resolução extrajudicial de conflitos, de forma adequada, ultrapassando o modelo adversarial característico das disputas jurídicas. Centra-se não no embate entre as partes, mas no consenso dialogado através da prática da argumentação e do entendimento, tidas como uma forma de reflexão do agir comunicativo. Tratase de um projeto social baseado na dignidade e retomada de responsabilidade, na medida em que permite a participação social através da reflexão individualizada dos conflitos e para além da busca de soluções, ainda que não jurídicas, porém práticas. 


\section{A IMPLEMENTAÇÃO DO PROGRAMA DE PROTEÇÃO E FACILITAÇÃO À CONVIVÊNCIA HARMÔNICA}

Dentro desse contexto, a Universidade Federal Fluminense, junto a Faculdade de Direito, desenvolve um laboratório de reflexões e experiências dentro de uma proposta de formação jurídica que busca ser essencialmente emancipadora e humanista, na medida em que visa demonstrar como a implantação de técnicas de resolução alternativas de conflito no ambiente do Núcleo de Prática Jurídica pode contribuir não só com a sociedade, mas também com a própria sustentabilidade do Poder Judiciário, "desjudicializando" conflitos, sem, contudo, limitar o acesso à justiça.

O Centro de Assistência Jurídica da UFF (CAJUFF) atende a população carente residente na municipalidade de Niterói. Além disso, é nesse ambiente que os alunos desenvolvem a disciplina curricular de prática laboratorial aprendendo, concretamente, a atuação profissional da área do direito.

Com a observação da atuação do Poder Judiciário e a atual crise, verifica-se que alguns processos seriam desnecessários se houvesse tentativa de resolução alternativa daquela controvérsia, mormente quando a natureza do conflito é familiar ou envolve direito de vizinhança. Buscando "desjudicializar" os conflitos, propõe-se um campo de diálogo entre as partes, orientadas pelos alunos e professores na busca de uma solução amigável do conflito. A recuperação da voz ativa das partes, num ambiente de liberdade comunicativa $^{6}$, de diálogo e respeito, promove a construção de um consenso responsável e legitimado pelos envolvidos, de forma democrática, fazendo com que o conflito real seja dissolvido de forma eficaz.

Foi nesse sentido que foi aprovada ação de extensão intitulada Programa de Proteção e Facilitação da Convivência Harmônica.

O Programa, diferentemente do núcleo de prática, não só atende a população carente, mas também está aberto a receber quaisquer pessoas em conflito, porém dispostas a solucioná-los pacificamente. Esta abertura foi possível justamente pela proposta de desjudicialização do conflito. Quando o

\footnotetext{
${ }^{6}$ Explica Jürgen Habermas (2010, p.155/156): “eu entendo a 'liberdade comunicativa' como a possibilidade - pressuposta no agir que se orienta pelo entendimento - de tomar posição frente aos proferimentos de um oponente e às pretensões de validade aí levantadas, que dependem de um reconhecimento intersubjetivo. (...) Liberdade comunicativa só existe entre atores que desejam entenderse entre si sobre algo num enfoque performativo e que contam com tomadas de posição perante pretensões de validade reciprocamente levantadas".
} 
conflito está judicializado, a observância do benefício da gratuidade de justiça cinge-se a aplicação literal da Lei 1.060/50.

A proposta pedagógica e metodológica é paradigmática: trabalhar com casos concretos trazidos pela comunidade local ou pelos mediadores. No desenvolvimento do projeto, serão realizadas sessões de conciliação e mediação, onde será oportunizado o diálogo entre as partes, possibilitando uma solução amigável e pacífica ao conflito.

$\mathrm{Na}$ hipótese do procedimento resultar em um consenso legitimado pelos envolvidos, será elaborado um termo de acordo para posterior requerimento de homologação judicial. Em hipótese contrária, as partes poderão ajuizar a ação pertinente junto ao Poder Judiciário, desde que hipossuficientes. Caso não o sejam, deverão procurar profissionais privados.

Sendo assim, a ação de extensão busca o diálogo entre os envolvidos no conflito, como forma de garantir o acesso à justiça e principalmente permitir aos participantes, através da prática do conhecimento, alcançar um viés emancipatório, para além da simples solução do conflito, atingindo também a efetividade ${ }^{7}$ do acesso à justiça e, por consequência, os direitos.

$\mathrm{Na}$ esteira da teoria de Habermas, o programa permite a administração intersubjetiva da razão de cada participante através de sessões de mediação, de modo que o entendimento se concretize no sentido dos enunciados argumentativos por ambos propostos, na busca da evolução do conflito, para reconstruir a convivência pacífica. Quando se permite às partes formar seu convencimento através de sua razão, do livre agir comunicativo, juntamente com o próprio consenso, advém uma expectativa legítima de validade e efetividade do mesmo. Enquanto o resultado da mediação traz essa expectativa legítima, o mesmo não podemos afirmar das sentenças prolatadas pelo órgão do Poder Judiciário, principalmente quando o caso se refere à relações continuadas, como as de família ou de vizinhança.

Nas sessões de mediação, oportuniza-se uma forma ímpar de se operar a razão de cada participante, de forma que eles sejam capazes de pensar e

\footnotetext{
${ }^{7}$ Quando se fala em efetividade o que se busca é a eficácia social da norma, o efeito gerado no mundo fático, a concreta produção de resultados. Para Luís Roberto Barroso (2001, p.85) "a efetividade significa a realização do Direito, o desempenho concreto de sua função social. Ela representa a materialização, no mundo dos fatos, dos preceitos legais e simboliza a aproximação, tão íntima quanto possivel, entre o dever-ser normativo e o ser da realidade social."
} 
propor os enunciados argumentativos em condições que garantam uma expectativa legítima de observância, propiciando com o tempo o entendimento e a reconstrução da relação afetada pelo conflito.

Por mais utópico que isto possa parecer, nas circunstâncias em que se encontra a sociedade e temendo seus rumos, a mediação é proposta como um mecanismo de transformação da própria realidade social e da prática da cidadania, favorecendo a concretização dos direitos humanos. Com efeito, compreendida como ação dirigida aos protagonistas dos conflitos sociais, a mediação propicia a abertura de um amplo debate sobre os antagonismos existentes no próprio seio da sociedade, possibilitando o diálogo e ampliação da compreensão das partes, transformando-se a situação adversarial em uma situação de cooperação, promovendo assim, o acesso à Justiça na sua forma mais eficaz, que é o gerenciamento e, possível, solução efetiva do conflito, resposta tão almejada pela sociedade e pelo próprio Direito.

A partir desses dados e constatações, após aprovação do programa, o mesmo se encontra em fase de implementação e desenvolvimento e recebe adeptos e contribuições relevantes a cada dia, tanto por parte dos graduandos, pós-graduandos e docentes, como também por parte da sociedade e dos mediandos.

Dessa forma, incentivam-se práticas sensíveis para resolução dos conflitos no CAJUFF, a partir de uma prática diferenciada, mas complementar ao atual ensino adversarial e litigioso. Os objetivos principais são verificar a possibilidade de uma nova proposta de ensino da prática jurídica, baseada na cooperação e no resgate da cidadania e responsabilidade dos envolvidos no litígio, além de analisar a implementação da mediação como método alternativo e adequado de resolução de conflitos no âmbito do núcleo de prática jurídica da Faculdade de Direito da Universidade Federal Fluminense, analisando descritivamente os resultados decorrentes de tal proposta.

Tendo em vista o projeto ainda estar em fase de implementação e desenvolvimento, os resultados esperados consistem no aproveitamento da utilização das técnicas da mediação para a abordagem de conflitos numa perspectiva diferenciada do atual ensino jurídico litigioso e o que se busca concluir é se tal prática tende a fortalecer o exercício da cidadania, por parte dos alunos, uma vez que complementa o ensino jurídico no sentido da busca 
pelo acesso à justiça, e dos próprios envolvidos na mediação, quando possibilita a retomada da responsabilidade e legitimação das decisões com base no consenso.

\section{CONSIDERAÇÕES FINAIS}

A partir dos dados da pesquisa teórica que resultou na submissão do projeto aprovado, chegou-se a conclusão de que a técnica da mediação extrajudicial tende a ser a mais adequada à resolução alternativa de controvérsias, tendo em vista sua natureza e finalidade de dissipar o conflito, dissolvendo a litigiosidade contida neste, sendo indicada em casos que envolvam relações continuadas, que tendem a permanecer após 0 procedimento, como é o caso de relações de vizinhança, escolares e, em especial, relações familiares.

Objetivando-se desconstruir os conflitos e restabelecer a convivência harmônica entre as partes, na esteira do discurso de Habermas, as sessões de mediação desenvolvidas no Núcleo de Prática da Universidade Federal Fluminense tem como escopo o viés emancipatório, em que as próprias partes, por meio do entendimento gerado pelo procedimento, poderão buscar uma real pacificação do conflito.

O consenso legitimado pelos mediandos, ausentes as figuras do vencedor e do vencido, com a possibilidade de uma relação social equilibrada posteriormente. $O$ procedimento de mediação como instrumento transformador de relação adversarial em relação colaborativa, facilitando o descortinar de soluções criativas e proporcionando aprendizado e esclarecimento das partes para, inclusive, prevenção de futuros conflitos.

Como decorrência lógica da mudança estrutural da nossa sociedade e da ampliação do conceito de acesso à justiça, para permitir a coexistência de meios alternativos de resolução de controvérsias, é fundamental a mudança de paradigmas do ensino jurídico no Brasil.

É imprescindível que seja incluído, como parte da formação do bacharel em Direito, futuro jurista e operador, seja por ação extensionista ou mesmo pela inclusão curricular, formas de administração de conflitos sem a necessidade de judicializá-los. 
Assim, sugere-se que o ensino jurídico se adeque a esse novo enfoque, sobretudo para possibilitar o caminho evolutivo e o acompanhamento da sociedade com as práticas coexistenciais de resolução de conflitos, evitando a falência de instituições e do próprio sistema do Direito.

E este é o grande objetivo deste estudo e principalmente do Programa de Proteção e Facilitação da Convivência Harmônica: permitir, no âmbito da extensão acadêmica, a partir de construções teóricas interdisciplinares, o contato real de discentes, docentes e sociedade civil a conflitos que possam atingir seu fim através da resolução alternativa, sem que seja necessário recorrer ao Poder Judiciário.

\section{REFERÊNCIAS BIBLIOGRÁFICAS}

BARROSO, Luís Roberto. O Direito Constitucional e a efetividade de suas normas. 5. ed. Rio de Janeiro: Renovar, 2001.

BAUMAN, Zygmunt. Modernidade líquida. Tradução de Plínio Dentzien. Rio de Janeiro: Zahar, 2001.

CAPPELLETTI, Mauro. Os métodos alternativos de solução de conflitos no quadro do movimento universal de Acesso à Justiça. Revista de Processo, São Paulo, o 74, ano 19, abril-junho de 1994, pp. 82-97.

. La dimensione sociale: l'accesso alla giustizia, in: Dimensioni della giustizia nelle società contemporenee. Bologna: Mulino, 1994, pp.71-102.

e GARTH, Bryant. Acesso à justiça. Tradução Ellen Gracie Northfleet. Porto Alegre: Fabris, 1988.

HABERMAS, Jürgen. Consciência moral e agir comunicativo. Tradução de Guido A. de Almeida. Rio de Janeiro: Tempo Brasileiro, 1989.

. Direito e democracia: entre facticidade e validade. Tradução de Flávio Beno Siebeneichler. Vol. I. 2.ed. Rio de Janeiro: Tempo Brasileiro, 2010.

HANSEN, Gilvan Luiz. A resolução de conflitos no Estado Democrático de Direito: uma perspectiva Habermasiana, in Direito e Filosofia - Diálogos. Zulmar Fachim e Clodomiro José Bannwart Júnior (coord.). Campinas: Editora Millennium, 2011, pp.99-120.

JEVEAUX, Geovany Cardoso. Uma Teoria da Justiça para o Acesso à Justiça. In: Uma Teoria da Justiça para o Acesso à Justiça. Geovany Cardoso Jeveaux (org.). Rio de Janeiro: GZ Ed., 2011, pp.1-110.

JUNQUEIRA, Eliane Botelho. "Acesso à Justiça: um olhar retrospectivo", in Revista Estudos Históricos. Número 18, 1996, pp.1-15. 
MUNIZ, Tânia Lobo. A ética na mediação.In: Mediação de conflitos. Paulo Borba Casella e Luciane M. de Souza (coord.), Belo Horizonte: Fórum, 2009, pp.103-117.

PINHO, Humberto Dalla Bernardina de. Teoria Geral da Mediação. Rio de Janeiro: Lumen Juris, 2008.

RODRIGUES, Horácio Wanderlei. Pensando o Direito no século XXI: diretrizes curriculares, projetos pedagógicos e outras questões pertinentes. Florianópolis, Fundação Boiteux, 2005.

SANTOS, Boaventura de Sousa. A Sociologia dos Tribunais e a Democratização da Justiça, in: Pela mão de Alice: o social e o político na pósmodernidade. 12. ed. São Paulo: Cortez, 2008, pp.161-185.

Cortez Editora, 2007.

Para uma Revolução Democrática da Justiça, São Paulo:

SARMENTO, Roselaine dos Santos. Mediação Familiar: um meio altamente eficaz de acesso à justiça. In: Família e Jurisdição. Eliene Ferreira Bastos e Asiel Henrique de Souza (coord.) Belo Horizonte: DelRey, 2005, pp.285-306.

VIANNA, Luiz Werneck; CARVALHO, Maria Alice Resende de; MELO, Manuela Pallacios Cunha; BURGOS, Marcelo Baumann. A judicialização da política e das relações sociais no Brasil. Rio de Janeiro: Renavan, 1999.

WATANABE, Kazuo. Acesso à justiça e sociedade moderna. In: Participação e processo. Ada Pellegrini Grinover, Cândico Rangel Dinamarco e Kazuo Watanabe (coord.). São Paulo: RT, 1988, pp.128-135.

A mentalidade e os meios de solução de conflitos no Brasil. In: Mediação e Gerenciamento do Processo. Ada Pellegrini Grinover; Kazuo Watanabe e Caetano Lagrasta Neto (coord.) São Paulo: Atlas, 2007, pp.06-10. 